\title{
Using Sensitivity Analysis to Improve the Efficiency of a Net-Zero Energy Vaccine Warehouse Design
}

\author{
David Pudleiner $^{a}$; Jonathan Colton ${ }^{a *}$ \\ ${ }^{a}$ G.W. Woodruff School of Mechanical Engineering, Georgia Institute of Technology, Atlanta, GA, 30332 \\ *Corresponding Author.Tel: +1-404-894-4707 Email: jcolton@gatech.edu
}

\begin{abstract}
A critical step in the design of a Net-Zero Energy building is the reduction of energy consumption, so that consumption can be cost-effectively offset by renewable energy production. In this paper, we present a method to inform the design of Net-Zero Energy buildings through the identification of influential energy efficiency measures. A regression-based global sensitivity analysis is used to quantify the relative importance of both individual design parameters and bilinear interactions between parameters. This allows for the identification of the specific twoway interactions between parameter pairs, rather than an evaluation of the influence of interactions for each parameter in a lumped manner as is commonly used in building performance simulation. The relative importance of both building control and architectural design parameters are assessed, and are used to help evaluate the importance of utilizing an integrated design method for reducing building energy consumption. The case-study building investigated is a primary vaccine warehouse, a vital part of the vaccine cold chain in the developing world. As this building type has not received adequate attention in the field of building performance simulation, this paper makes a significant contribution towards an improved understanding of the energy efficient design of these warehouses.
\end{abstract}

Keywords: Net-Zero Energy, Sensitivity Analysis, Uncertainty Analysis, Vaccine Warehouse, EnergyPlus, Multivariate Regression

\section{Introduction}

The concept of the Net-Zero Energy building is a promising solution towards reducing the substantial energy consumption of our built environment. As a result, these sustainable buildings have recently begun to receive significant attention from the international community [1-3]. A vital step in the design process of a Net-Zero Energy facility is the reduction of the building energy consumption through the use of energy efficiency measures $[4,5]$. Building energy modeling can play a key role in the identification of potential energy efficiency measures, and can help to ensure that design decisions are informed by the impact that that they will have on the building energy consumption. However, while it is widely accepted that energy modeling is an integral component of any performance-based design process, it is often underutilized in 
design practice to help identify the most influential energy efficiency measures and in turn guide the focus of resources towards the most promising solution space.

The first way in which the utility of energy modeling is reduced in practice is the method by which it is applied. In a study of methodological approaches to designing environmentally sustainable buildings, Hansen and Knudstrup conclude that the most common way that energy modeling is implemented is by using a case-based approach [6]. In this type of approach, several design concepts are created and then energy modeling is used to help select the best solution, possibly with minor modifications. With this type of reactive approach, the ability of building simulation to inform design decisions is severely limited, as there is no way to exploit a greater understanding of how the design parameters impact energy consumption. An improved approach that generates such an understanding is the combined use of uncertainty and sensitivity analysis. Uncertainty analysis allows for the characterization of uncertainty in a model output as a result of variations in model inputs, and sensitivity analysis allows for the identification of the relative importance of each input in determining the output uncertainty. Together, these two complimentary analysis techniques can quantitatively inform a designer how each parameter under consideration will impact building energy consumption. This type of analysis is also highly valuable for informing analysis in later NZE design stages, such as cost-effectively optimizing renewable energy supply and building energy efficiency. The sensitivity analysis increases the effectiveness and efficiency of such optimizations, focusing designers on a select group of influential parameters.

Several previous studies in the literature advocate for the use of uncertainty and/or sensitivity analysis as a valuable method for informing the building design process [7-10]. Shen and Tzempelikos studied the relative importance of a variety of design parameters on the building thermal and lighting energy performance on private offices in Philadelphia [9]. The results of their sensitivity analysis indicate that window-to-floor ratio and glazing type are the driving parameters in determining total energy consumption for all tested orientations except when the office faces south. Hygh et al. used a regression-based sensitivity analysis to investigate the annual energy consumption of an office building across five climate zones in the US [10]. The results of their study suggest that a multivariate regression model can be used as a suitable substitute for running numerous ad hoc building models during early design. As a result, both the sensitivity analysis formed from the regression model and the model itself can be used to help guide the design of the facility early in the process. While studies such as these show the value of sensitivity analysis in theory for prioritizing energy efficiency measures, Attia et al. examined the effectiveness of sensitivity analysis for informing Net-Zero Energy design in practice [12]. This was done through focus group experiments with architectural engineers, professors, and students. They found that for the architectural engineers, the use of building performance simulation coupled with sensitivity analysis reduced the energy consumption of all proposed designs by an average of $48 \%$, as compared to designs in which the groups were not 
given any building performance simulation tools. This supports the value of building performance simulation coupled with sensitivity analysis not only in theory, but also in practice.

A second limitation of current energy modeling methods is the design space that is analyzed. In the design of a new building, the common impression exists that the most important characteristics for determining its energy efficiency are the physical design parameters such as the insulation thickness and window glazing properties [13]. However, several recent studies emphasize that building operational control variables, such as temperature set-points, can also have a substantial impact on energy consumption [13-15]. Wang et al. [14] investigated the impact of changes in operations-related variables including HVAC controls, lighting controls, and plug loads on the energy consumption of an office building across four US climate zones. The results of the analysis indicate that the HVAC controls, such as temperature set-points, are highly influential and can increase the building energy consumption by as much as $70 \%$. Ruiz et al. compared the relative importance of uncertainty in several different types of variables, including physical design parameters and operational variables, on the energy consumption of an office building in several European climates [15]. They determined that the heating temperature set-point is the third most influential parameter for determining the fuel consumption of the building in Lisbon, with only the window and wall U-Values being more significant. Studies such as these support the analysis of building control parameters during design, and show that ignoring variation in this parameter type can neglect potentially large energy savings.

Unlike physical design parameters, building operational control variables can be actively changed during the life stages of the building post construction, such as during commissioning, operations, and maintenance. For instance, a study conducted on 20 daylit spaces in the Midwest found considerable discrepancies between how the spaces were designed to function, and how they in fact functioned as a result of improper commissioning [16]. By re-commissioning the systems, the authors were able to improve the median energy savings of the systems from $23 \%$ to $63 \%$, as compared to using no daylighting. A substantial variation in building energy consumption as a result of changes in building control parameters emphasizes the importance of an integrated design method in producing a Net-Zero Energy building. In an integrated design method, the personnel responsible for the building post construction are actively involved in the building design process [17], including individuals such as the building manager and the building owner. The inclusion of these individuals allows for them to buy-in to the performance goals of the project, in order to help increase the chances that the building will be commissioned and maintained as designed.

This paper proposes an improved method to quantify the impacts of a large number of design parameters on building energy consumption, an integral part of the Net-Zero Energy building design process. A Monte Carlo-based uncertainty and sensitivity analysis is used to quantify the relative importance of 31 architectural design and 13 building control parameters. Through the use of a multivariate regression including bilinear terms, the relative importance of both individual parameters and interactions between parameter pairs is quantified. While main 
effects regressions are commonly used for sensitivity analysis [10,11, 18], no previous sensitivity analyses including bilinear interactions were found in the building performance simulation literature. It should be noted that though previous regression-based analyses in building performance analysis have included interaction terms [10, 19], these did not include bilinear interaction terms in the regression from which sensitivity indices are calculated. The inclusion of bilinear interaction terms allows the design team to gain an improved understanding of the influential energy efficiency measures, as the analysis indicates not only whether interactions are important, but which specific ones are influential.

The proposed method is applied to the case study of a primary vaccine storage warehouse, a key component of the vaccine supply chain in developing countries [20]. As an extensive set of building control and architectural design parameters is studied, this analysis allows for an assessment of the relative importance of an integrated design method for this building type. The primary vaccine warehouse is a building type which has received minimal attention in the field of building performance simulation, as the only two previous studies that examine this building type $[21,22]$, were conducted as part of the same project as the research in this paper. Therefore, this study contributes to both the building performance simulation and global health domains, as the results can be used to help inform the design of energy efficient primary vaccine warehouses. The demanding design environment of the developing world highlights the importance of using building energy modeling to inform the selection of energy efficiency measures. Due to the inherent resource limitations of working within this context, it is imperative that the available resources are focused on the most promising means for reducing building energy consumption.

\section{Methodology}

\subsection{Outline of Methodology}

The relative importance of the design parameters for a primary vaccine warehouse building type was investigated through a case study method. This case study used the recently drafted layout submitted to the Tunisian Ministry of Health for a new national vaccine warehouse. Figure 1 shows the framework of the methodology implemented in this paper. It was assumed that the draft layout is representative of the primary vaccine warehouse building type, and so was used as the preliminary building layout. From this layout, an energy model of the building was constructed in EnergyPlus as a result of the widespread usage of this software and support from experimental validation [12, 23-25]. Following the construction of the baseline model, the relevant input parameters for variation were selected and their probability distributions defined. A Monte-Carlo Analysis (MCA) method was used to propagate the input uncertainties through the EnergyPlus mode and to produce an output distribution for the warehouse total annual energy consumption. To conduct the sensitivity analysis, both main 
effects and bilinear multivariate regressions were used to identify influential parameters and interactions.

The entire process of conducting the uncertainty and sensitivity analysis was automated in Matlab. This allowed for a considerable reduction in the amount of time required for the numerous steps within the analysis, such as the creation and simulation of the building energy models. A high performance desktop computer was used to execute the analysis, and allowed for eight EnergyPlus simulations to be run in parallel. As a result, approximately 12 hours were required to run the analysis for each location examined.

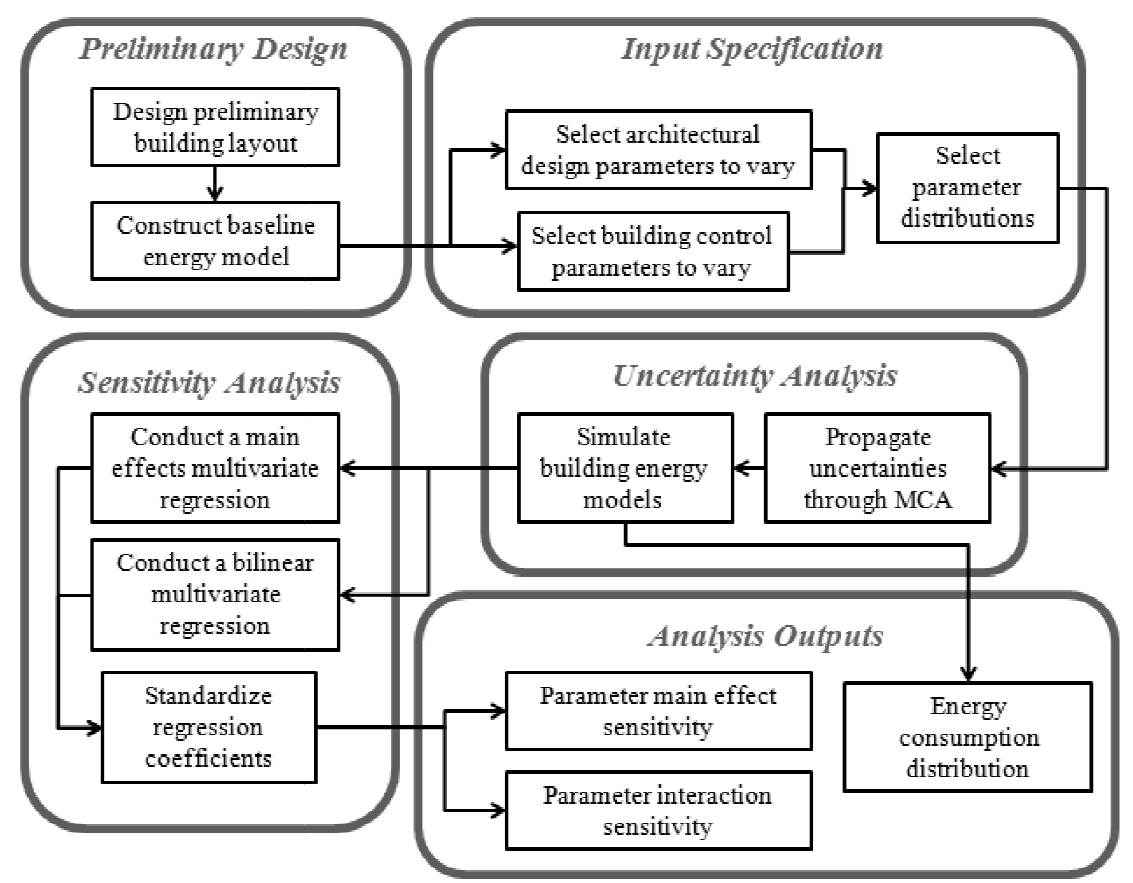

Figure 1. Framework for the proposed uncertainty and sensitivity analysis method

\subsection{Case Study Building}

The primary vaccine warehouse is a unique building type due to the multiple, distinct thermal zones contained within the building. As a result of the different supplies that must be stored in a primary vaccine warehouse, the general layout of the building encompasses four different temperature zones: a Frozen Storage zone for vaccine kept between $-15^{\circ} \mathrm{C}$ and $-25^{\circ} \mathrm{C}$ [26], a Chilled Storage zone for vaccine kept from $2-8^{\circ} \mathrm{C}$ [20], a Controlled Room Temperature (CRT) zone for vaccine diluents kept between $15^{\circ} \mathrm{C}$ and $25^{\circ} \mathrm{C}$ [20], and a Dry Product zone. Unlike the other zones, the temperature range of the Dry Product zone is not mandated by guidelines from global health literature. As shown by floor plans of the case study building in Figure 2, these four zones occupy a majority of the building floor area. However, to make the 
building a self-sufficient facility, the plans also include an office mezzanine, restrooms, a workshop and a plant area.

The warehouse has a flat roof and an internal ceiling height of $6.85 \mathrm{~m}$, with the mezzanine floor $3 \mathrm{~m}$ above the ground floor. Goods enter the warehouse through two overhead doors which are each $2.5 \mathrm{~m}$ wide by $3 \mathrm{~m}$ tall. In this layout, the Frozen Storage, Chilled Storage, and CRT zones are all walk-in storage areas. The walls and ceilings of all the walk-in zones are assumed to be constructed of structurally insulated panels (SIP), with a $100 \mathrm{~mm}$ air gap in between the panels and adjacent vertical walls, or cladding, such as the exterior warehouse wall on the east side of the Chilled Storage zone. Both the Frozen Storage and Chilled Storage zones are each assumed to be conditioned by two independent split refrigeration systems to ensure a level of redundancy in case a system fails, as is common practice in the vaccine storage industry. The Chilled Storage and CRT Storage zones have an internal height of $6 \mathrm{~m}$, while the Frozen Storage zone has an internal height of only $3 \mathrm{~m}$ due to the utilization of shelving storage instead of racking as is assumed for all other storage zones. Table 1 shows the floor area and volume for each zone in the model, as well as the baseline thermostat set-points for all zones assumed in the creation of the layout. All of the zones are conditioned within a set temperature range except for the Plant zone, which is assumed to be unoccupied and houses the supporting infrastructure for the building. The warehouse has a total conditioned floor area of $768 \mathrm{~m}^{2}$, including the mezzanine floor area.

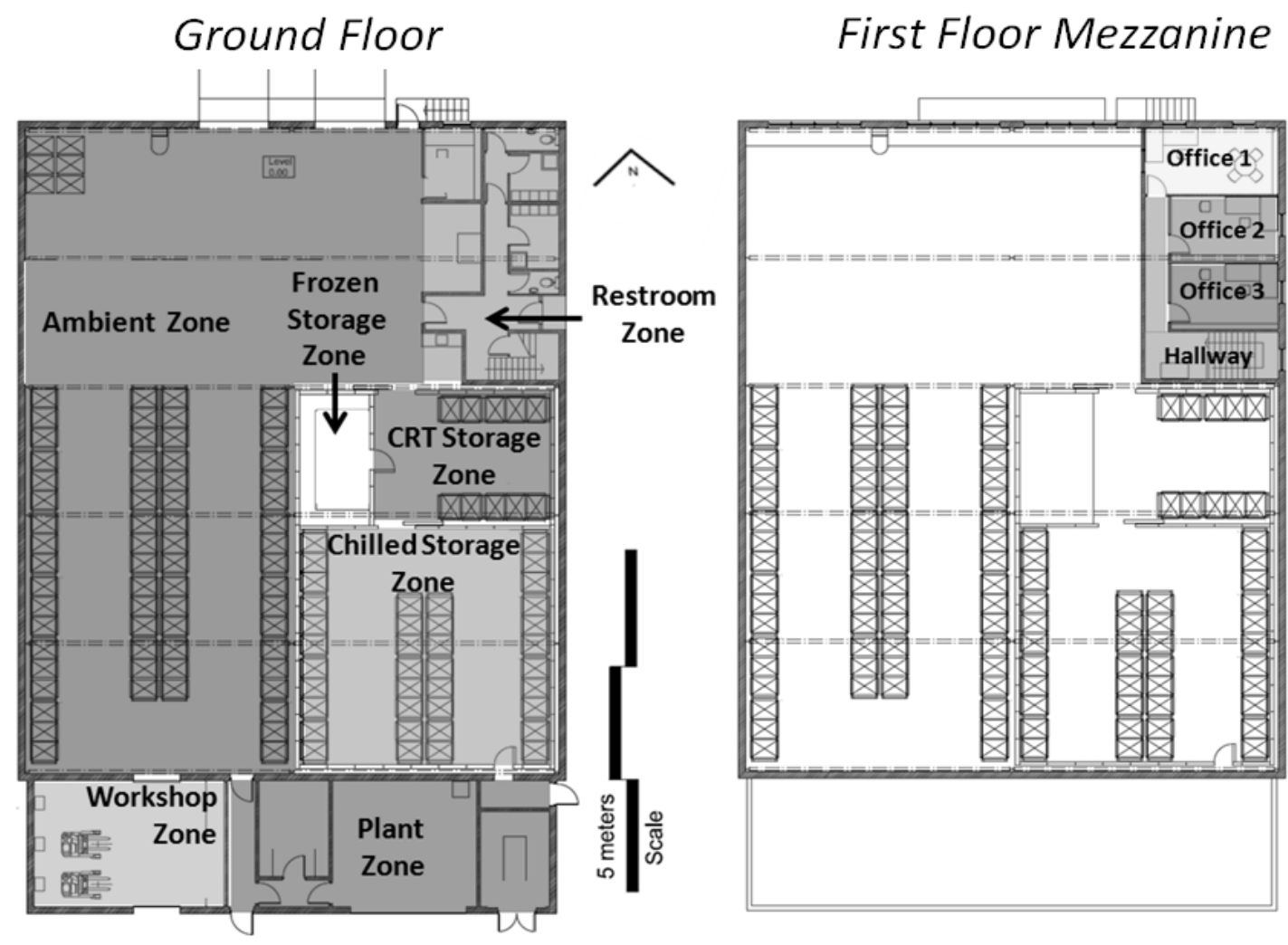


Figure 2. Ground floor (left) and first floor (right) floor plans for the case study building. North arrow indicates the building orientation in the Northern Hemisphere ' nations, while in the Southern Hemisphere locations the orientation is rotated by 180 estory glazing faces south.

Table 1. Floor area, volume and baseline thermal set-points for each zone included in the model

\begin{tabular}{llllll}
\hline Zone Group & Zone & $\begin{array}{l}\text { Floor } \\
\text { Area }\left(\mathbf{m}^{2}\right)\end{array}$ & $\begin{array}{l}\text { Volume } \\
\left(\mathbf{m}^{\mathbf{3}}\right)\end{array}$ & $\begin{array}{l}\text { Baseline Heating } \\
\text { Set-Point }\left({ }^{\circ} \mathbf{C}\right)\end{array}$ & $\begin{array}{l}\text { Baseline Cooling } \\
\text { Set-Point }\left({ }^{\circ} \mathbf{C}\right)\end{array}$ \\
\hline $\begin{array}{lllll}\text { Walk-In } \\
\text { Storage Zones }\end{array}$ & Chilled Storage & 113.1 & 678.8 & 2 & 8 \\
& CRT Storage & 46.5 & 279.0 & 15 & 25 \\
& Frozen Storage & 18.1 & 54.4 & -25 & -15 \\
Warehouse & Dry Product & 414.1 & $3,011.6$ & & \\
Zones & Restroom & 62.7 & 188.1 & 15 & 32 \\
& Workshop & 49.2 & 172.1 & & \\
Unconditioned & & & & & Not Applicable \\
Zones & Plant & 82.9 & 290.1 & Not Applicable & \\
& & & & & 26 \\
& Office 1 & 16.4 & 62.0 & & $(32$ night setback $)$ \\
Office Zones & Office 2 & 13.6 & 52.5 & 20 & \\
& Office 3 & 14.3 & 55.1 & $(15$ night setback $)$ & \\
& Hallway & 20.0 & 71.7 & & \\
\hline
\end{tabular}

\subsection{Building Energy Model}

The building energy model of the case study warehouse was constructed in EnergyPlus using the floor plan shown in Figure 2. To construct the model, it was assumed that each area labeled is an individual thermal zone within the model. Therefore, the model comprised a total of 11 thermal zones, each of which is assumed to be well-mixed so that temperatures are spatially uniform within a zone. While the warehouse equipment is constantly online to maintain vaccines and supplies at their proper temperatures, the building is only occupied for a portion of the day. The warehouse is assumed to be occupied for six days a week, from 8 AM to 5 PM with a one hour lunch break. Each of the office zones is assumed to be occupied by one person during working hours; an occupancy density of one person per $100 \mathrm{~m}^{2}$ [27] is assumed for all other zones in the building except for the Plant zone. Two sources of plug load are included in the model: office equipment and electric fork lift trucks. Both the average power density and the schedule for the office plug loads are varied as part of the uncertainty analysis, and are discussed further in the following sub-section. The plug load from the fork lift trucks is calculated assuming one truck with an average power consumption of $1.25 \mathrm{~kW}$ [28] is used during working hours and that the fork lift charger has a charging efficiency of 75\% [29]. The heat load from the operation of the fork lift is distributed as a function of floor area to all storage zones that use pallet racking storage: Dry Product Storage, CRT Storage, and Chilled Storage. 
The infiltration of air through the building envelope is modeled as a constant air change per hour rate. It is assumed that no permeation of air through the walls of the Walk-In Storage Zones occurs. Instead, the doorways are modeled as the sole source of infiltration for these zones. All walk-in storage doors are assumed to implement strip curtains, which are modeled as having a $90 \%$ effectiveness in preventing mixing of air between two zones [30]. The Frozen Storage door is assumed to be open for four minutes out of every operational hour [31], while the Chilled Storage and CRT Storage doors are both assumed to be open for eight and a half minutes out of every operational hour [22].

While previous studies have shown the advantages of skylights for warehouses [32], they were not investigated in this paper as the roof space was assumed to be reserved for solar panel placement to assist in the formulation of a Net-Zero Energy building. Instead, north facing clerestory glazing was investigated for daylighting the Dry Product zone. This glazing is mounted above the overhead warehouse doors shown in the ground floor plan in Figure 2, and is modeled as a ribbon of glazing along the entire length of the Dry Product zone north wall. For the climates investigated that are located the Southern hemisphere, the orientation of the building is rotated 180 degrees so that the clerestory glazing maintains a similar function in all locations. Daylighting was also investigated in the office zones through the use of windows, which are modeled as horizontal ribbon strips along the width of each exterior office wall.

To heat and cool the building zones, the Ideal Loads Air method in EnergyPlus is used. In this method, the heating, air-conditioning, and refrigeration loads of the building are calculated assuming $100 \%$ efficiency, and are then converted into electricity consumption through the use of a Coefficient of Performance (COP). A constant COP was assumed for the heating equipment in the calculation of the electricity required to heat the Office Zones, Warehouse Zones, and CRT zone for each time step of the simulation. Similarly, a constant $\mathrm{COP}$ was assumed for the air-conditioning equipment to cool these zones. However, for the two zones which were assumed to be maintained by dedicated refrigeration equipment, the Chilled Storage zone and the Frozen Storage zone, dynamic COPs were calculated for improved accuracy. Details about the calculation of the cooling load and COPs for these two zones can be found in Appendix A.

\subsection{Defining the Input Variations (Design Space)}

For the uncertainty analysis, a total of 31 architectural design and 13 building control parameters were investigated. As a minimal amount of information exists on the energy consumption of vaccine warehouses, this parameter set conservatively includes a large number of design variables which are influential for similar building types [10, 14, 22, 33]. The architectural design parameters included were all assumed to be continuous variables, and can be classified into the following categories: opaque envelope thermal properties, window properties, infiltration and natural ventilation, equipment Coefficients of Performance (COPs), and zone 
lighting power densities. Orientation was omitted as a variable due to the utilization of a predefined layout for the case study. The clerestory glazing was designed to face north in Tunis, and so to maintain consistency across locations the clerestory glazing is facing north in the Northern Hemisphere and south in the Southern Hemisphere. The window properties investigated include Window to Wall Ratio (WWR), Solar Heat Gain Coefficient (SHGC), and Shading Projection Factor (SPF). The SPF is used as a pseudo parameter for varying the depth of a horizontal window overhang, and is defined as the ratio between the window height and the overhang depth.

Uniform distributions were assumed for all of the architectural design parameters, since no previous knowledge about the probability distributions of these parameters was found for vaccine storage warehouses. The use of uniform distributions therefore ensures the least bias on the results of the analysis, as it does not assume any more information other than the maximum and minimum parameter values. In addition, the use of uniform distributions in a design parameter uncertainty analysis is recommended in building performance literature, as different values of the design variables within the range of interest can all be regarded as equally probable [25]. Table 2 lists the lower and upper boundaries of the uniform distributions explored for the architectural design parameters. These bounds were selected so that the range investigated for each variable encompasses the plausible design space currently available.

A similar approach was used for the building control parameters; however, several discrete control variables were investigated. For these parameters, two levels were assumed, a baseline control level and an improved control level. To remain consistent with the mindset of the distribution selection for continuous variables, an equal probability was assumed for each of the two levels. Three categories of discrete building control parameters were investigated: evaporator fan control, defrost control, and lighting sensors.

Table 3 provides a summary of the baseline and improved control levels for the discrete control parameters investigated. For the Chilled Storage evaporator fan control, the baseline strategy is that the evaporator fans inside the cold room are operated constantly whether the compressors are in the on or off portion of their cycle, as is the current operating practice in a recently commissioned Tunisian medical warehouse [22]. The only time that the fans do not run is when the entrance door to the zone is open. For the improved efficiency option the evaporator fans are assumed to cycle on and off with the compressors, so that they operate only when the compressor is running. Due to the large height and volume of the Chilled Storage zone, destratification fans are constantly operated in the improved evaporator control scheme to maintain a uniform temperature distribution. The total evaporator fan power in the Chilled Storage room is $3.76 \mathrm{~kW}$, assuming electronically commutated fans, and the total destratification fan power is $124 \mathrm{~W}$ [22]. In addition to the four discrete building control parameters varied, nine continuous building control parameters were included in the uncertainty analysis as shown in Table 4. These parameters were classified into three categories: thermostat control, plug loads, and lighting control. In accordance with the definition of building control parameters established 
in the previous section, a design team is able to exert influence on all of these parameters through an integrated design process involving the building owner and manager; however, all of these parameters are subject to active variation during the life stages of the building post construction.

Table 2. Lower and upper boundaries for the architectural design parameters investigated

\begin{tabular}{|c|c|c|c|c|}
\hline Category & Design Parameter & Units & Lower Bound & Upper Bound \\
\hline \multirow{13}{*}{$\begin{array}{l}\text { Opaque } \\
\text { Envelope } \\
\text { Thermal } \\
\text { Properties }\end{array}$} & External Wall Insulation U-value & $\mathrm{W} /\left(\mathrm{m}^{2}-\mathrm{K}\right)$ & 0.18 & 5 \\
\hline & External Wall Thermal Mass & $\mathrm{J} /\left(\mathrm{m}^{2}-\mathrm{K}\right)$ & 10,000 & 404,000 \\
\hline & External Wall Solar Absorptance & ---- & 0 & 0.95 \\
\hline & Overhead Door Insulation U-Value & $\mathrm{W} /\left(\mathrm{m}^{2}-\mathrm{K}\right)$ & 0.25 & 5 \\
\hline & Roof Insulation U-Value & $\mathrm{W} /\left(\mathrm{m}^{2}-\mathrm{K}\right)$ & 0.18 & 5 \\
\hline & Roof Thermal Mass & $\mathrm{J} / \mathrm{K}$ & 10,000 & 404,000 \\
\hline & Roof Solar Absorptance & ---- & 0 & 0.95 \\
\hline & Partition Wall U-Value & $\mathrm{W} /\left(\mathrm{m}^{2}-\mathrm{K}\right)$ & 0.33 & 5 \\
\hline & Mezzanine Floor U-Value & $\mathrm{W} /\left(\mathrm{m}^{2}-\mathrm{K}\right)$ & 0.33 & 5 \\
\hline & Walk-In Storage Wall U-value & $\mathrm{W} /\left(\mathrm{m}^{2}-\mathrm{K}\right)$ & 0.14 & 0.5 \\
\hline & Walk-In Storage Door U-value & $\mathrm{W} /\left(\mathrm{m}^{2}-\mathrm{K}\right)$ & 0.18 & 0.5 \\
\hline & Frozen Storage Floor U-Value & $\mathrm{W} /\left(\mathrm{m}^{2}-\mathrm{K}\right)$ & 0.16 & 0.66 \\
\hline & Chilled Storage Floor U-Value & $\mathrm{W} /\left(\mathrm{m}^{2}-\mathrm{K}\right)$ & 0.22 & 5 \\
\hline \multirow{10}{*}{$\begin{array}{l}\text { Window } \\
\text { Properties }\end{array}$} & Warehouse Clerestory WWR & ---- & 0.5 & 40 \\
\hline & Warehouse Clerestory U-value & $\mathrm{W} /\left(\mathrm{m}^{2}-\mathrm{K}\right)$ & 0.6 & 6.17 \\
\hline & Warehouse Clerestory SHGC & ---- & 0.15 & 0.81 \\
\hline & Office Front Windows WWR & ---- & 1 & 40 \\
\hline & Office Front Windows U-Value & $\mathrm{W} /\left(\mathrm{m}^{2}-\mathrm{K}\right)$ & 0.6 & 6.17 \\
\hline & Office Front Windows SHGC & ---- & 0.15 & 0.81 \\
\hline & Office Side Windows WWR & ----- & 1 & 40 \\
\hline & Office Side Windows U-Value & $\mathrm{W} /\left(\mathrm{m}^{2}-\mathrm{K}\right)$ & 0.6 & 6.17 \\
\hline & Office Side Windows SHGC & ---- & 0.15 & 0.81 \\
\hline & Office Side Window SPF & ---- & 0.05 & 1 \\
\hline \multirow{2}{*}{$\begin{array}{l}\text { Infiltration \& } \\
\text { Natural } \\
\text { Ventilation }\end{array}$} & Natural Ventilation & $\mathrm{ACH}$ & 0 & 20 \\
\hline & Infiltration & $(\mathrm{L} / \mathrm{s}) / \mathrm{m}^{2}$ & 0.175 & 0.7 \\
\hline \multirow{2}{*}{ Lighting } & Office Lighting Power Density & $\mathrm{W} / \mathrm{m}^{2}$ & 9.7 & 10.8 \\
\hline & Warehouse Lighting Power Density & $\mathrm{W} / \mathrm{m}^{2}$ & 6.5 & 8.6 \\
\hline \multirow{4}{*}{ Equipment COPs } & $\begin{array}{l}\text { Frozen Storage Refrigeration System } \\
- \text { Rated COP }\end{array}$ & ---- & 1.48 & 2.14 \\
\hline & $\begin{array}{l}\text { Chilled Storage Refrigeration System } \\
\text { - Rated COP }\end{array}$ & ---- & 2.77 & 3.31 \\
\hline & A/C System - Average COP & ---- & 2.9 & 3.86 \\
\hline & Heat Pump - Average COP & ---- & 3.5 & 4.18 \\
\hline
\end{tabular}


Table 3. Lower and upper bounds for the discrete building control parameters investigated

\begin{tabular}{llll}
\hline Category & Parameter & Baseline Control & Improved Control \\
\hline $\begin{array}{l}\text { Evaporator } \\
\text { Fan Control }\end{array}$ & $\begin{array}{l}\text { Chilled Storage } \\
\text { Evaporator Fan Control }\end{array}$ & $\begin{array}{l}\text { Fans constantly operate, except } \\
\text { when the door is open }\end{array}$ & $\begin{array}{l}\text { Fans cycle on and off with cooling, } \\
\text { thermal destratification fans added }\end{array}$ \\
$\begin{array}{l}\text { Chilled Storage } \\
\text { Controst }\end{array}$ & $\begin{array}{l}\text { Defrost Control } \\
\text { Frozen Storage } \\
\text { Defrost Control }\end{array}$ & $\begin{array}{l}\text { Scheduled defrost for } \\
\text { Schinutes each day } \\
20 \text { minutes each day }\end{array}$ & $\begin{array}{l}\text { Defrost terminates prior to } \\
\text { scheduled time if all ice is melted } \\
\text { Defrost terminates prior to } \\
\text { scheduled time if all ice is melted }\end{array}$ \\
$\begin{array}{l}\text { Lighting } \\
\text { Control }\end{array}$ & $\begin{array}{l}\text { Occupancy Sensing } \\
\text { Light Control }\end{array}$ & $\begin{array}{l}\text { No occupancy sensors } \\
\text { for any zone }\end{array}$ & Occupancy sensors for all zones \\
\hline
\end{tabular}

Table 4. Lower and upper bounds for the continuous building control parameters investigated

\begin{tabular}{lllll}
\hline Category & Parameter & Units & Lower Bound & Upper Bound \\
\hline \multirow{4}{*}{ Thermostat } & Heating Temperature Set-point (Warehouse Zones) & ${ }^{\circ} \mathrm{C}$ & 15 & 18 \\
& Heating Temperature Set-point (Office Zones) & ${ }^{\circ} \mathrm{C}$ & 20 & 22 \\
& Cooling Temperature Set-point (Warehouse Zones) & ${ }^{\circ} \mathrm{C}$ & 26 & 32 \\
& Cooling Temperature Set-point (Office Zones) & ${ }^{\circ} \mathrm{C}$ & 23 & 25 \\
& Night Setback Heating Temperature (Office Zones) & ${ }^{\circ} \mathrm{C}$ & 12.7 & 18.3 \\
& Night Setback Cooling Temperature (Office zones) & ${ }^{\circ} \mathrm{C}$ & 26.7 & 30 \\
& & & & 21 \\
Plug Loads & Plug Load Density (Office zones) & $\mathrm{W} / \mathrm{m}^{2}$ & 2.3 & 20 \\
& Plug Load Level at Night (Office zones) & $\%$ & 5 & \\
Lighting & & & & 300 \\
Control & Daylighting Illuminance Set-Point (Dry Product zone) & $1 \mathrm{lux}$ & 100 & 300 \\
\hline
\end{tabular}

\subsection{Monte-Carlo Uncertainty Analysis}

After the applicable parameters and ranges for variation were selected, a single MonteCarlo analysis (MCA) for each location examined was used to examine the effect of input parameter uncertainty on the building energy consumption. The annual energy consumption of the building was selected as the output parameter of interest since the objective of the sensitivity analysis is to identify influential design parameters to help obtain Net-Zero Energy on an annual basis. The annual energy consumption was obtained through simulation of the building energy model over the course of an entire year with a Typical Meteorological Year (TMY) file used to define the weather conditions. An inherent assumption in the selection of this sole output is that the grid connection is maintained constantly. Although grid connectivity in the developing world is an issue, primary vaccine warehouses are likely to be located in large cities with established grids, thus this is deemed a reasonable assumption. A Latin Hypercube Sampling 
(LHS) method was implemented due to its efficient stratification properties, which allow for the use of more computationally demanding models such as EnergyPlus because a large amount of sensitivity and uncertainty information can be obtained with a relatively small sample size [34]. A total of 1,000 simulations were created for the MCA using LHS to randomly sample from the distributions of all 44 parameters simultaneously. While a larger number of simulations was feasible, previous building performance studies have determined that additional simulations beyond 1,000 have diminishing returns on improving the accuracy of a sensitivity analysis based on the Monte Carlo results [10, 22].

\subsection{Regression-Based Sensitivity Analysis}

A multivariate linear regression method was used to examine the sensitivity of the building energy consumption to the variations in each of the design parameters. This technique was selected because of the wide use of regression-based methods in the field of building performance analysis [25]. In addition, this type of sensitivity analysis is relatively fast and easy to understand, both of which are significant advantages towards its application in building design. First, a bi-directional, stepwise regression was conducted to examine the main effects of the design variables. The regression produces an equation of the form shown in Equation 1:

$$
E_{\text {total }}\left(x_{1}, x_{2}, \ldots, x_{n}\right)=B_{0}+\sum_{i=1}^{n} B_{i} x_{i}
$$

where $E_{\text {total }}$ is the total building energy consumption, $x_{i}$ is the value of design variable $i, B_{0}$ is the y-intercept, $B_{i}$ is the regression coefficient for the design variable, and $n$ is the number of design variables kept after the stepwise regression process.

While the regression coefficients indicate the sensitivity of the model to each parameter, they do not provide an index that can be used to compa

re the relative importance of the parameters to help inform designers. This is due to the inherent bias in the magnitude of the regression coefficient as a result of the scale and units used for each parameter. To compare the relative importance of the parameters, the method of standardized regression coefficients was selected to transform the raw coefficients. In this method, the coefficients from Equation 1 are standardized using Equation 2:

$$
\operatorname{SRC}_{i}\left(x_{i}, E_{\text {Total }}\right)=\frac{B_{i} \sigma_{i}}{\sigma_{\text {Total }}}
$$

where $S R C_{i}$ is the standardized regression coefficient, $\sigma_{\text {Total }}$ is the standard deviation of the output energy consumption from the MCA, and $\sigma_{i}$ is the standard deviation of the input parameter $i$. 
An additional stepwise regression was conducted to examine the interactions between significant parameters. Only the first order interaction terms were considered because previous research has shown that higher order interaction terms were less important in comparison [35]. First order interactions were examined through the addition of bi-linear interaction terms as shown in Equation 3:

$$
X=x_{a} x_{b}
$$

where $X$ is an interaction between two different design parameters, $x_{a}$ and $x_{b}$. Therefore, the regression equation with bilinear interactions takes the form of Equation 4:

$$
E_{\text {total }}\left(x_{1}, x_{2}, \ldots, x_{n}\right)=B_{0}+\sum_{i=1}^{n} B_{i} x_{i}+\sum_{j=1}^{p} B_{j} X_{j}
$$

where $p$ is the total number of significant interactions.

Equation 2 also was used to standardize the raw coefficients of the interaction regression, with the only modification being that the interaction coefficients are multiplied by the standard deviation of both parameters participating in the interaction. The SRC of an interaction term then can be directly compared to the main effect SRCs, to evaluate the relative importance of the interaction. While unnecessary for the first order sensitivity analysis based on Equation 1, in order for the sensitivity indices calculated from Equation 4 to be meaningful, the input distribution for each of the continuous parameters was mean-centered prior to the stepwise regression. This allows the SRCs for the main effects and interactions to be calculated at the average values of all continuous parameters [36], ensuring consistent main effect SRCs between the two regressions.

\subsection{Exploration Across Multiple Climates}

In order to examine how the average annual climate affects the results of the uncertainty and sensitivity analysis, four additional locations were selected for examination in addition to the case study location of Tunis, Tunisia: Bangkok, Thailand; Mombasa, Kenya; Asuncion, Paraguay; and Buenos Aires, Argentina. All of the selected cities are within a country listed by the United States Agency for International Development (USAID) as a developing country or an advanced developing country [38, 39]. These specific locations were selected based upon their substantial differences in Heating Degree Days (HDDs) and Cooling Degree Days (CDDs) as shown in Table 5. Together, this group encompasses the full spectrum of variation for warm and hot climates in the developing/transitional world, as Bangkok is the hottest location for which a TMY weather file is available and Buenos Aires is at the low boundary of the Warm climate zone as defined by ASHRAE international standards [40]. 
Table 5. Cooling Degree Days (CDD) and Heating Degree Days (HDD) for the five locations examined

\begin{tabular}{llllll}
\hline & Buenos Aires & Tunis & Asuncion & Mombasa & Bangkok \\
\hline $\mathrm{CDD} 10^{\circ} \mathrm{C}$ & 2597 & 3432 & 4841 & 5959 & 6950 \\
$\mathrm{HDD} 18^{\circ} \mathrm{C}$ & 1211 & 814 & 254 & 0 & 0 \\
\hline
\end{tabular}

\section{Uncertainty Analysis Results}

The results of the Monte Carlo-based uncertainty analysis for each location are shown by the histograms in Figure 3. Due to the large number of data points used in MCA, the histogram shape is assumed to be representative of the Probability Distribution Function (PDF) for the warehouse energy consumption within the design space examined. As illustrated by Figure 3, the distribution for each of the climates examined has a distinctly bimodal shape. This shape indicates that one of the discrete building control parameters investigated has an overwhelmingly large influence on the warehouse energy consumption, resulting in the two distinct portions of each distribution. This is confirmed by the results of the sensitivity analyses, as discussed in Section 4, which show that the SRC for the Chilled storage evaporator fan control is considerably larger than the SRC for all other parameters. Therefore, for analysis the energy consumption distribution for each location has been divided into two portions based on the level of the Chilled Storage evaporator fan control as detailed in Table 3. The D2 portion of the distribution in each histogram corresponds to the baseline evaporator fan strategy, and the D1 portion of the distribution corresponds to the improved evaporator fan strategy.

Several properties of the distributions for each location are summarized inTable 6 . The results show that, in general, the range of the total distribution, as well as the standard deviation of each portion of the distribution, increases as the number of CDDs increases. The increase in these metrics is a result of the higher variation in cooling loads present in the warmer climates, and is in part explained by the increasing influence of interactions for the hot climates as discussed further in the following section. Table 6also shows that in general, the difference between the means of D1 and D2, $\mu_{D 2}-\mu_{D 1}$, decreases as the climates warm. This agrees with expectations, due to the higher refrigeration cooling load and subsequent increased evaporator fan use in hotter climates for the control strategy in which the evaporator fans cycle with cooling load (D1).

The uncertainty distribution is a valuable tool during design, as it can be used to estimate the potential for reductions in building energy consumption within the design space under consideration. This can help to inform the selection of energy savings goals, a key step in the procedure for any performance-based design [41]. In addition, since the sensitivity analysis results are standardized by the standard deviation of the uncertainty analysis, together the results of these analyses provide the designer with a quantitative understanding of the influence of each parameter on building energy consumption. 

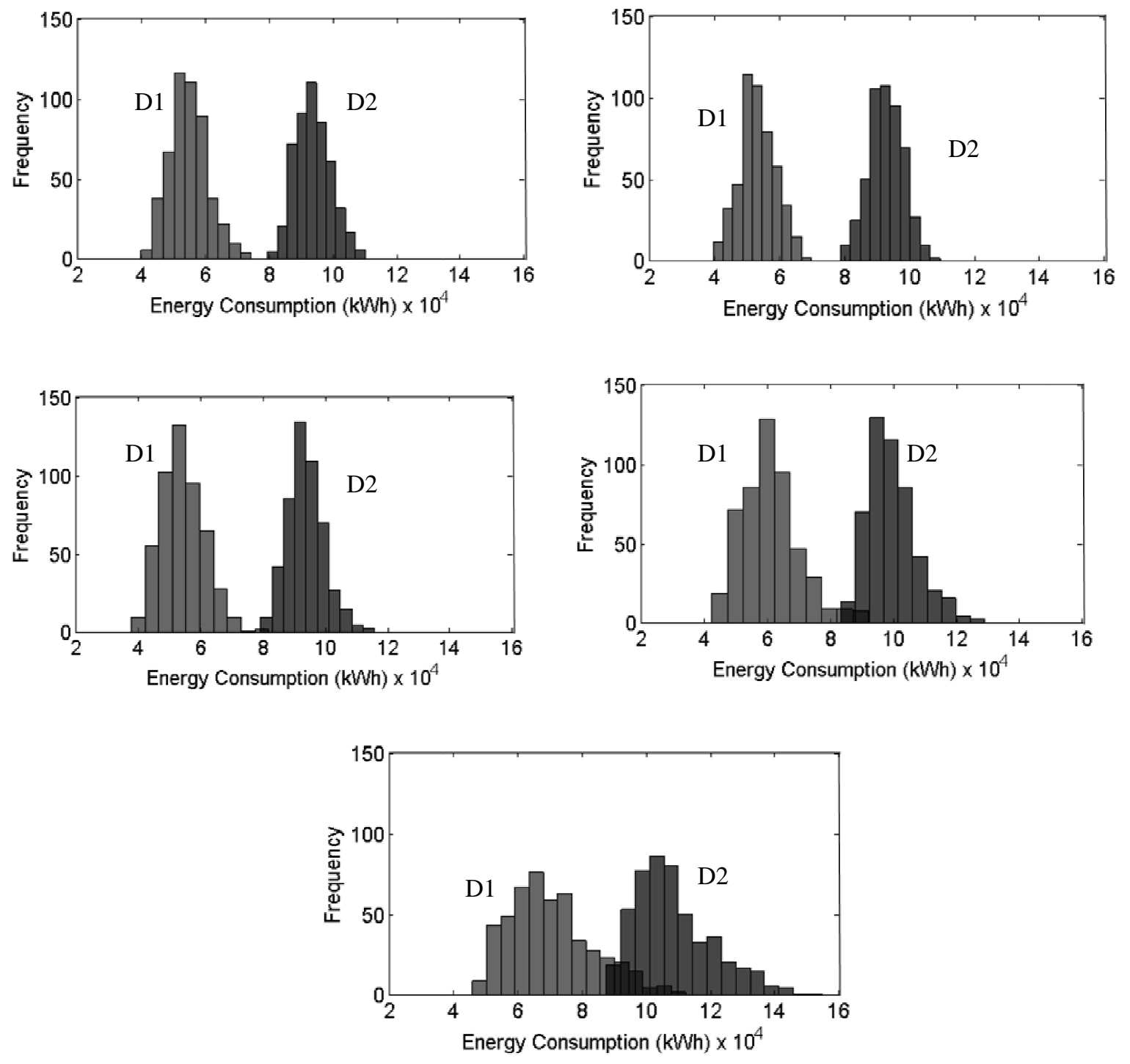

Figure 3. Histograms of the output energy consumption; Buenos Aires (top left), Tunis (top right), Asuncion (middle left), Mombasa (middle right), Bangkok (bottom)

Table 6. Properties of the energy consumption distributions each location

\begin{tabular}{|c|c|c|c|c|c|c|}
\hline & & \multirow{2}{*}{$\begin{array}{l}\quad \text { Warm } \\
\text { Buenos } \\
\text { Aires }\end{array}$} & \multirow[b]{2}{*}{ Tunis } & \multirow[b]{2}{*}{ Asuncion } & \multicolumn{2}{|c|}{ Extremely Hot } \\
\hline & & & & & Mombasa & Bangkok \\
\hline $\begin{array}{l}\text { D1 Portion of } \\
\text { the Distribution }\end{array}$ & $\begin{array}{l}\text { Mean }(\mathrm{kWh}) \\
\text { Standard Deviation }(\mathrm{kWh})\end{array}$ & $\begin{array}{l}54,793 \\
5,889\end{array}$ & $\begin{array}{l}53,309 \\
5,535\end{array}$ & $\begin{array}{l}54,308 \\
6,732\end{array}$ & $\begin{array}{l}61,016 \\
9,100\end{array}$ & $\begin{array}{l}70,490 \\
13,004\end{array}$ \\
\hline $\begin{array}{l}\text { D2 Portion of } \\
\text { the Distribution }\end{array}$ & $\begin{array}{l}\text { Mean }(\mathrm{kWh}) \\
\text { Standard Deviation }(\mathrm{kWh})\end{array}$ & $\begin{array}{l}93,626 \\
5,475\end{array}$ & $\begin{array}{l}92,659 \\
5,184\end{array}$ & $\begin{array}{l}93,464 \\
5,851\end{array}$ & $\begin{array}{l}99,318 \\
7,734\end{array}$ & $\begin{array}{l}108,532 \\
12,213\end{array}$ \\
\hline
\end{tabular}




\begin{tabular}{|c|c|c|c|c|c|c|}
\hline $\begin{array}{l}\text { Total } \\
\text { Distribution }\end{array}$ & $\begin{array}{l}\text { D1\&D2 Mean Difference }(\mathrm{kWh}) \\
\text { Total Range }(\mathrm{kWh})\end{array}$ & $\begin{array}{l}38,833 \\
69,926\end{array}$ & $\begin{array}{l}39,350 \\
69,506\end{array}$ & $\begin{array}{l}39,256 \\
77,593\end{array}$ & $\begin{array}{l}38,302 \\
86,027\end{array}$ & $\begin{array}{l}38,042 \\
108,325\end{array}$ \\
\hline
\end{tabular}

\section{Sensitivity Analysis Results}

\subsection{Series 1 Parameter Main Effects Regression}

To identify the influential parameters and interactions, three series of regressions were used, with each series consisting of a single regression for each location. The first series of main effect regressions, referred to as Series 1, considers the entire 44 parameter design space. All of these regressions have $R^{2}$ values of at least 0.95 , indicating that nearly all of the energy consumption variation observed in the model can be accounted for by the main effects of the parameters. The SRCs of these regressions for all locations reveal that the Chilled Storage evaporator fan control is the most influential parameter, as shown in Figure 4, and is responsible for the bimodal shape of the histograms in Figure 3. At a minimum, the evaporator fan SRC magnitude is two and a half times larger, as shown by the results for Bangkok. In the more moderate climates, such as Buenos Aires and Tunis, the SRC for the evaporator fan control is over six times greater than the SRC for the second most influential parameter.

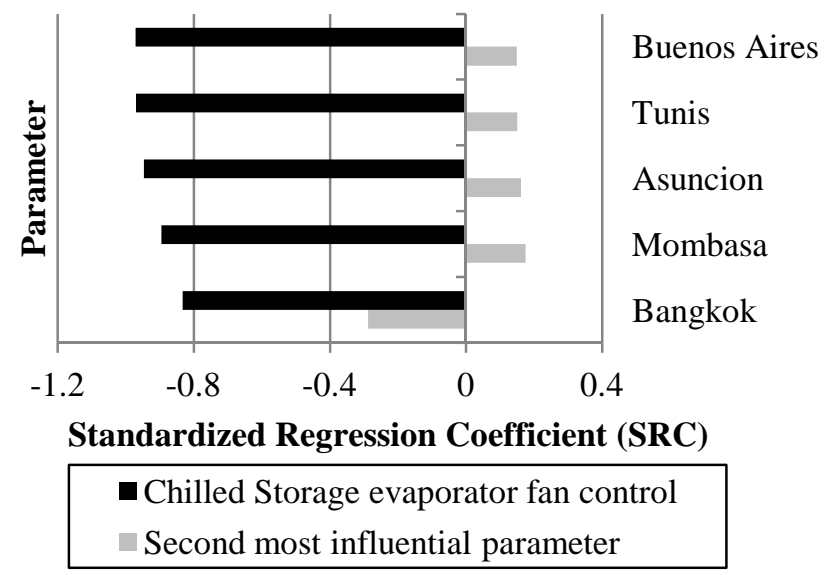

Figure 4. Series 1 main effect sensitivity analysis SRCs for the two most influential parameters in each location; a positive SRC indicates a positive correlation between the parameter and the warehouse energy consumption.

A comparison between the relative importance of the architectural design and building control parameters can be made by comparing these two parameter groups on the basis of the amount of variance in the output data that is explained by the main effects of each parameter type. This is done using Equation 5: 


$$
R^{2}=\sum_{i=1}^{n}\left(\beta_{i} r_{i}\right)^{2}
$$

where $R^{2}$ is the coefficient of determination, $\beta_{i}$ is the standardized regression coefficient for parameter $i, r_{i}$ is the correlation coefficient for parameter $i$, and $n$ is the total number of parameters in the final stepwise regression equation.

As $\mathrm{R}^{2}$ indicates the amount of output variation explained by the regression model, this equation can be used to determine the relative amount of output variation correlated with each parameter input group by calculating the relative contribution of the parameter types to the coefficient of determination. Table 7 shows the relative contributions of the architectural design parameters $\left(R_{A D}^{2}\right)$ and the building control parameters $\left(R_{B C}^{2}\right)$ for the Series 1 regression. Due to the dominance of the evaporator fan control, the building control parameters are considerably more influential than the architectural design parameters. The influence of the building control parameters is largest in Tunis, where this group accounts for approximately $95 \%$ of the variation in energy consumption. The high relative importance of the building control parameters emphasizes the importance of an integrated design process for the creation of an energy efficient primary vaccine storage warehouse.

Table 7. $\mathrm{R}^{2}{ }_{\mathrm{AD}}$ and $\mathrm{R}_{\mathrm{BC}}^{2}$ for the Series 1 main effects regression

\begin{tabular}{llllll}
\hline & Buenos Aires & Tunis & Asuncion & Mombasa & Bangkok \\
\hline$R_{A D}^{2}$ & 0.05 & 0.04 & 0.06 & 0.10 & 0.16 \\
$R_{B C}^{2}$ & 0.94 & 0.95 & 0.92 & 0.86 & 0.80 \\
\hline
\end{tabular}

\subsection{Series 2 Parameter Main Effects Regression}

As a result of the dominating effect of the Chilled Storage evaporator fan control level on the warehouse energy consumption in all climates, a second series of main effects regressions was conducted on the D1 portion of the distribution in which the fans are at the more efficient control level. This progression illustrates how global sensitivity analysis should be applied iteratively in practice as design decisions progress to actively reflect the design space under consideration [6]. These Series 2 regressions provide an improved interpretation of the relative importance of the remaining parameters within the design space, as well as a comparison of the relative importance of the building control and architectural design parameters without the uncharacteristically large influence of the evaporator fan control. While the $\mathrm{R}^{2}$ values for the Series 2 regressions in each location are all smaller than the respective values of $\mathrm{R}^{2}$ for the Series 1 regressions, a value of at least 0.84 is maintained for all of the regressions. Therefore, they are deemed useful for the purposes of a main effects sensitivity analysis, as for the majority of applications, a regression model is considered acceptable when $\mathrm{R}^{2}$ is greater than 0.7 [42]. 
Table 8 shows the relative contribution of the architectural design parameters $\left(R_{A D}^{2}\right)$ and the building control parameters $\left(R_{B C}^{2}\right)$ to the Series 2 energy consumption variation. The results in this table show that without the uncharacteristically large influence of the evaporator fan control level, the relative importance of the building control parameters has substantially decreased. For this series, the value of $R_{B C}^{2}$ is less than $R_{A D}^{2}$ for all climates examined, with $R_{A D}^{2}$ on average accounting for more than three times more variation in the output energy consumption. However, even though the building control parameters are not of equal or greater importance, they are far from inconsequential in comparison to the architectural design parameters. The ratio of $R_{B C}^{2} / R_{A D}^{2}$ is highest in Bangkok, where the variation accounted for by the building control parameters is approximately half of that by the architectural design parameters. In addition, for all locations, the value of $R_{B C}^{2}$ indicates that the most influential building control parameters account for at least $17 \%$ of the variation observed in the warehouse energy consumption. Therefore, even without the evaporator fan control, the results show that meaningful reductions in the building energy consumption are possible with efficient building control parameters.

Table 8. $\mathrm{R}^{2}{ }_{\mathrm{AD}}$ and $\mathrm{R}_{\mathrm{BC}}^{2}$ for the Series 2 main effects regression

\begin{tabular}{llllll}
\hline & Buenos Aires & Tunis & Asuncion & Mombasa & Bangkok \\
\hline$R_{A D}^{2}$ & 0.69 & 0.70 & 0.69 & 0.65 & 0.58 \\
$R_{B C}^{2}$ & 0.23 & 0.21 & 0.17 & 0.19 & 0.27 \\
\hline
\end{tabular}

The Standardized Regression Coefficients for the most influential parameters in each climate are shown in Figure 5. The most important parameter for all of the climates examined, except for Bangkok, is the U-value of the walls/ceiling for the Walk-In Storage Zones. Additional influential architectural design parameters include parameters related to the U-value and solar absorptance of the warehouse envelope, as well as the warehouse lighting. This mix of results shows that while the energy consumption of the Walk-In Storage Zones is influential as expected due to their low temperatures, these parameters are not the exclusive focus for reducing the building's energy consumption. These results highlight the importance of considering a wide design space and using an analytical method to focus resources on influential design parameters, rather than using intuition.

The results also indicate several advantageous trends for the design of energy efficient vaccine storage warehouses in the developing world. Foremost, in the three hottest climates the roof solar absorptance is one of the three most influential parameters, and in Bangkok it is the most influential parameter. This trend is particularly advantageous for warehouses that aim to achieve Net-Zero Energy, as it shows that the placement of solar panels on the roof can function as both a renewable energy source and an important energy efficiency measure by shading the roof at the same time. The external wall solar absorptance also has a high relative influence for 
the two hottest climates of Mombasa and Bangkok. This shows that while the roof often receives the majority of attention for solar absorptance and shading considerations, the energy consumption for this building type can be sensitive to these properties for the entire envelope.

Another trend observed in the results is the high relative impact of the heating or cooling set-point for the Warehouse Zones (Dry Product, Warehouse, and Restroom zones) in all of the climates examined. Either the warehouse heating or cooling set-point is the second most influential building control variable, including the evaporator fan control, for every climate examined. This trend is advantageous for warehouses in the developing world, due to the wider range of thermal comfort acceptable to most individuals in developing countries as opposed to individuals in the developed world [43]. For instance, Givoni suggests that while the comfort zone for individuals in developed countries may only extend to $25^{\circ} \mathrm{C}$ in the summer, those in the developing world will be comfortable with temperatures up to $27^{\circ} \mathrm{C}$; with relative humidity below 70\%. Therefore, the Warehouse Zones of the facility may be able to use more energy efficient heating and cooling set points in the developing world without negatively impacting occupant thermal comfort. 


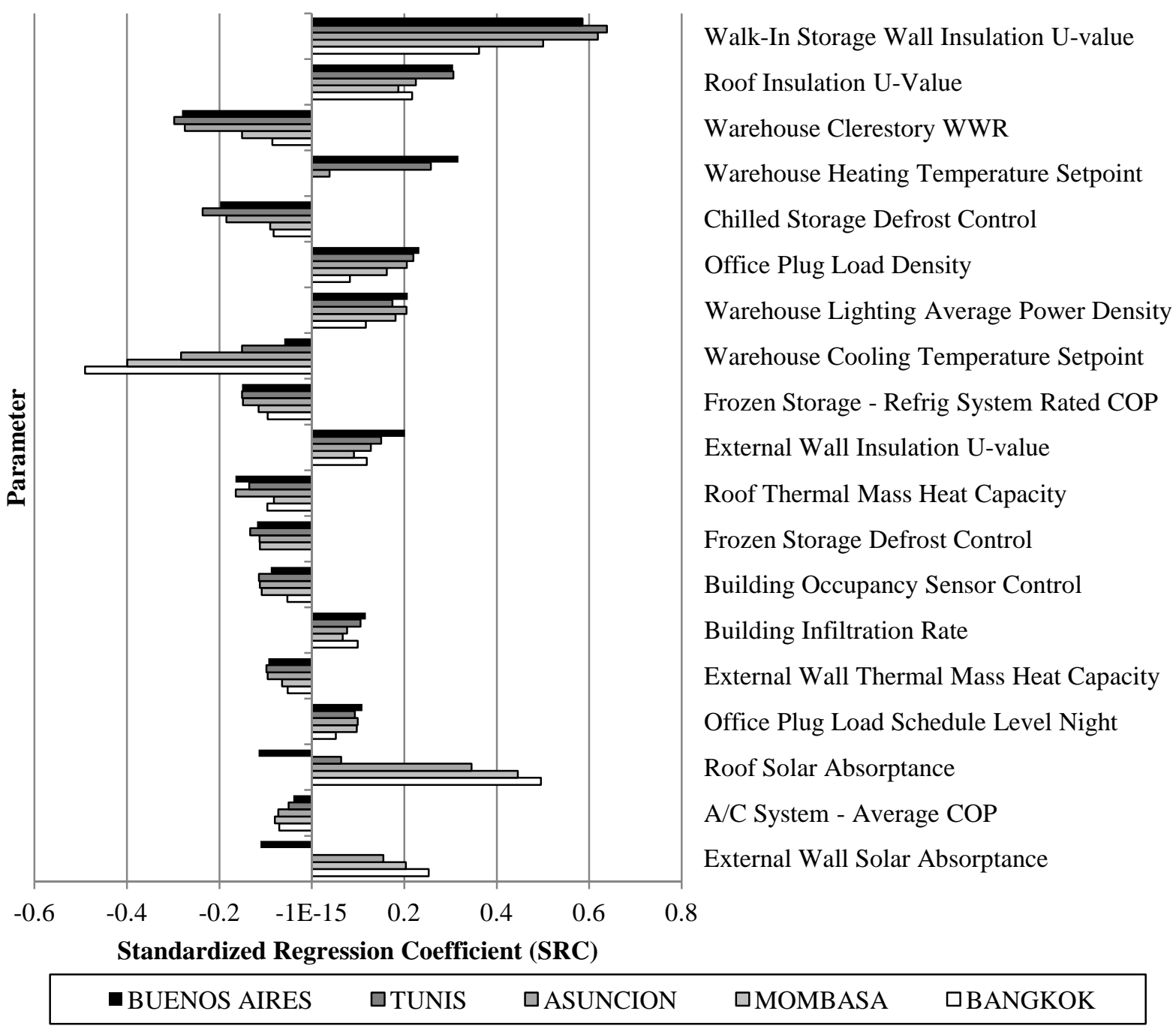

Figure 5. SRCs for the most influential parameters in the Series 2 main effects regression. Parameters ordered from top to bottom based on their relative influence in Tunis, which represents a warm climate.

\subsection{Series 3 Parameter Interactions Regression}

A third series of regressions including both main effects and interactions was conducted across the same design space as the Series 2 regressions. Therefore, the results of the Series 3 regressions show the additional insight that can be provided to designers through the examination of bilinear interactions in comparison to main effects alone. A list of the Series 3 $\mathrm{SRC}$ values for each climate in descending order is included in Appendix B. In general, the results indicate that as the number of CDDs increase, the importance of interactions also increases. This is supported by the larger discrepancies between the $\mathrm{R}^{2}$ values of the Series 2 and Series 3 regressions for hotter climates as shown by Figure 6 . While inclusion of the interaction terms explains an additional $3 \%$ of the variation of the regression model for Buenos Aires, in Bangkok the interaction terms account for over $11 \%$ of the variation in energy 
consumption. Overall, the most prominent interactions observed are between roof parameters, such as the roof solar absorptance and roof insulation U-value. In addition, there is a large presence of interactions between the roof parameters and the warehouse cooling set-point temperature.

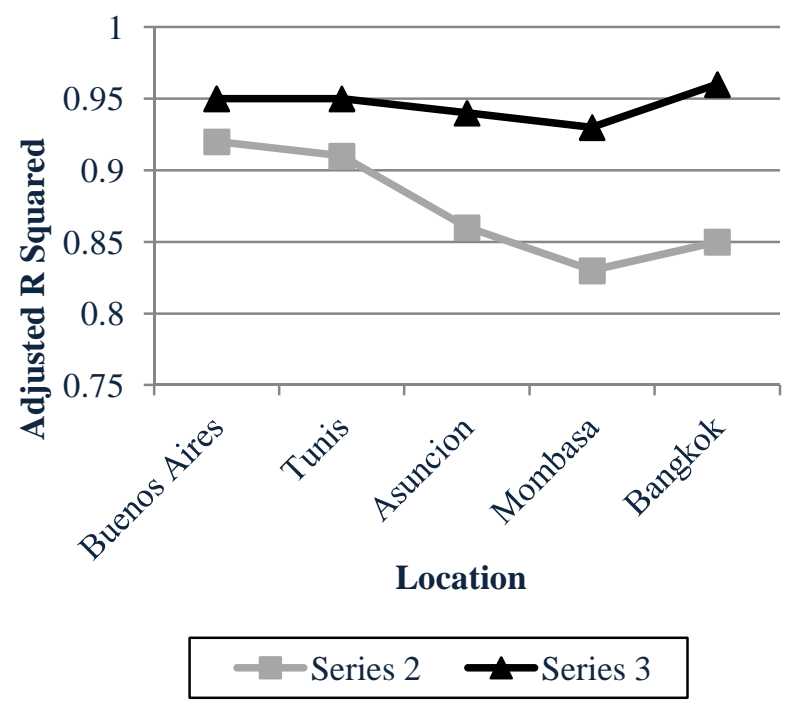

Figure 6. $\mathrm{R}^{2}$ values for the Series 2 main effect and Series 3 interaction regressions

As interaction terms are most influential in Bangkok, the SRCs for the five most influential parameters and two most important interactions in this climate are shown in Figure 7. Both of these interactions are more important than the sixth most influential individual parameter, and so supersede the majority of first order terms in importance. The Series 3 results for this location show that the most influential interaction is between the roof insulation U-value and the roof solar absorptance with a SRC of 0.19. While the main effects indicate that both of these parameters are influential in reducing the warehouse energy consumption, the interaction reveals that investment in one of these energy efficiency measures reduces the importance of the second parameter. With a SRC of 0.23 for the roof insulation, a low roof solar absorptance substantially decreases the impact that the roof insulation has on the warehouse energy consumption. The same conclusion of the decreased importance of the roof insulation U-value could be obtained by re-running the global sensitivity analysis after selecting a low solar absorptance for the roof due to the higher relative importance of the roof solar absorptance (SRC $=0.49$ ). However, this requires extra time for a new set of simulations. Therefore, the interaction results help to keep the sensitivity analysis results relevant with less iteration, as they allow the design team to better understand how modification in one design parameter will influence the rest of the system. This can reduce the time required for analysis, and potentially result in a faster progression of the building design. 


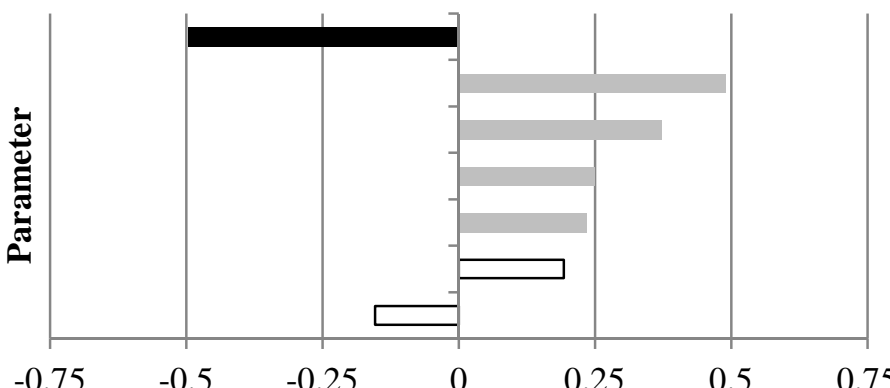

Warehouse Cooling Temperature Set-Point (CTSP)

Roof Solar Absorptance

Walk-In Storage Wall IUV

External Wall Solar Absorptance

Roof Insulation U-Value (IUV)

Roof IUV * Roof Solar Absorptance

Roof Solar Absorptance * Warehouse CTSP

Standardized Regression Coefficient (SRC)
Architectural
Building Control
Interaction

Figure 7. Bangkok Series 3 Standardized Regression Coefficients

A Rrduction in the roof solar absorptance also has a considerable impact on the SRC of the warehouse cooling temperature set-point for the results of Bangkok, as the SRC for the roof solar absorptance * warehouse cooling set-point temperature term is -0.15 . Since the SRC for the warehouse cooling temperature set-point is 0.50 , decreasing the roof solar absorptance by one standard deviation from the average value reduces the SRC for the cooling set-point to 0.35, so that its relative importance is below that of the walk-in wall insulation U-Value $(\mathrm{SRC}=0.37)$. The interaction between the roof solar absorptance and the warehouse cooling temperature setpoint is even more influential in Mombasa, as in this location the first order term for the warehouse cooling set-point $(\mathrm{SRC}=0.38)$ is only approximately twice as large as the interaction term $(\mathrm{SRC}=0.18)$. Interactions such as these between a building control parameter and an architectural design parameter further illustrate the importance of considering both parameter types during building design. The presence of significant bilinear interactions between parameters from each group can help the designer to identify ways to improve the robustness of the building energy consumption to changes in the building control parameters during commissioning and operation, reducing the reliance on an integrated design process. By contrast, the absence of such interactions further emphasizes the importance of an integrated design process, if building control parameter main effects are found to be significant.

\section{Conclusions}

Through a vaccine warehouse design case study, this paper demonstrates an improved uncertainty and sensitivity analysis method for informing the design of energy efficient buildings. The results of the research indicate that building control parameters, which are subject to active variation post construction, have a greater influence on reducing the energy 
consumption of these warehouses than architectural design parameters due to the dominance of the evaporator fan control strategy. These results are consistent throughout all of the climates examined, which range from warm-humid to extremely hot and humid. Therefore, an integrated design method, in which the personnel responsible for the building post construction, such as the building manager and owner, is recommended for this building type. Additional influential parameters for primary vaccine warehouses include the heating and cooling set-points for the Warehouse Zones, Walk-In Storage wall insulation U-Value, and roof solar absorptance. The analysis of bilinear terms indicates that interactions are most influential in hot climates, as a result of substantial interactions between roof parameters, as well as between the Warehouse Zones cooling temperature set-point and the roof parameters. The results of this research are limited by the sparse amount of information available for creating the building control parameter variations. More research examining the uncertainty of building control parameters is needed to ensure that realistic distributions are utilized and increase the confidence that can be placed in results.

The method demonstrated in this paper allows for the identification of specific interactions between parameter pairs in addition to a general evaluation of the importance of interactions for the design space considered. As a result, the inclusion of influential interactions can help to potentially reduce the number of times that a sensitivity analysis must be iteratively applied in practice, due to the improved understanding for how parameter sensitivities will vary as design choices are made. In addition, examining interactions between building control and architectural design parameters provides insight into ways in which the designer can improve the robustness of the building by mitigating the influence of building control variables and in turn reduce the reliance on an integrated design method. While this paper focuses on a building within the context of Net-Zero Energy design, the method demonstrated is not limited to this specific domain. The framework of the method can be adapted to any design seeking to better understand the impact of a large parameter set on building performance.

\section{Acknowledgments}

The authors would like to thank the Bill and Melinda Gates Foundation for partially funding this research from grant number OPP1060817, as well as the World Health Organization for its support of the project. In addition, special thanks is extended to Dr. Ramzi Ouhichi, Andrew Garnett, Steve McCarney, John Lloyd and Krystal Dillon, all of whom helped in the formulation of the warehouse layout used in this paper. Lastly, thank you to Dr. Jason Brown for his assistance in revising this paper. 
Appendix A: Calculation of Cooling Loads and COPs for the Chilled and Frozen Storage Zones For each simulation time step, a coefficient of performance $C O P_{\text {refrig }}$ was calculated for each of these zones according to Equation A.1 [44]:

$$
\operatorname{COP}_{\text {refrig }}=\operatorname{COP}_{\text {Nom }}\left(1.7603-0.0377 * T_{\text {Cond }}+0.0004 * T_{\text {Cond }}^{2}\right)
$$

where $\mathrm{COP}_{\text {Nom }}$ is the nominal refrigeration $\mathrm{COP}$ and $T_{\text {Cond }}$ is the condensing temperature. The condensing temperature is calculated using Equation A.2, which is of similar form to that used by Stoekle to calculate the condensing temperature in a refrigerated warehouse study [31]. $T_{\text {Cond }}$ is calculated as a function of $T_{d b}$, which is the outdoor air dry bulb temperature in degrees Celsius.

$$
\text { If } T_{d b}>10, \quad T_{\text {cond }}=T_{d b}+10 \quad ; \text { Else } \ldots \quad T_{\text {cond }}=20
$$

While the Ideal Loads Air method properly accounts for the latent load in nonrefrigerated zones, this method does not account for the freezing of moisture on the coils of the evaporators in zones served by refrigeration equipment. Therefore, Equation A.3 was used to account for the latent component of the coil loads $Q_{\text {coill,latent }}$ in these zones [30]:

$$
Q_{\text {coill,latent }}=m_{\text {Infiltration }} \Delta h_{\text {IceToVapor }}\left(W_{\text {InfilAir }}-W_{\text {ColdRoomAir }}\right)
$$

where $m_{\text {Infiltration }}$ is the mass of infiltrating air, $\Delta h_{\text {IceToVapor }}$ is the latent heat absorbed to change from ice to vapor, $W_{\text {ZoneAir }}$ is the humidity ratio of the infiltration air, and $W_{\text {ColdRoomAir }}$ is the humidity ratio of the cold storage room air. In order to calculate the defrost loads for the Chilled Storage and Frozen Storage zones, the accumulation of ice on the evaporator coils $M_{\text {Ice }}$ was calculated using Equation A.4 [30]:

$$
M_{\text {Ice }}=\dot{m}_{\text {Infiltration }}\left(W_{\text {InfilAir }}-W_{\text {ColdRoomAir }}\right) \Delta t
$$

where $\dot{m}_{\text {Infiltration }}$ is the mass flow rate of infiltrating air during a simulation timestep and $\Delta t$ is the length of the simulation timestep. For both zones, an electric coil defrost method was assumed with an effectiveness of 0.7 [30] for the electric heating element. The use of Equations A.1-A.4 to accurately predict the energy consumption for refrigeration equipment was validated in a previous study conducted on a refrigerated warehouse with split systems [22]. 


\section{Appendix B: Standardized Regression Coefficients for each climate}

Table B.1 through Table B.5 shows the 15 most influential terms in the bilinear interaction regressions for each climate.

TableB.1. 15 most sensitive terms in the bilinear sensitivity analysis for Buenos Aires

\begin{tabular}{ll}
\hline Main Effect/Interaction & SRC \\
\hline Walk-In Storage Wall Insulation U-value & 0.58 \\
Warehouse Clerestory WWR & -0.32 \\
Roof Insulation U-Value & 0.31 \\
Warehouse Heating Temperature Setpoint & 0.30 \\
Office Plug Load Density & 0.22 \\
Warehouse Lighting Average Power Density & 0.21 \\
Chilled Storage Defrost Control & -0.20 \\
External Wall Insulation U-value & 0.19 \\
Roof Thermal Mass Heat Capacity & -0.16 \\
Frozen Storage - Refrigeration System Rated COP & -0.15 \\
Roof Solar Absorptance & -0.12 \\
Frozen Storage Defrost Control & -0.12 \\
Building Infiltration Rate & 0.12 \\
Building Occupancy Sensor Control & -0.11 \\
Heat Pump - Average COP & -0.10 \\
\hline
\end{tabular}

TableB.2. 15 most sensitive terms in the bilinear sensitivity analysis for Tunis

\begin{tabular}{ll}
\hline Main Effect/Interaction & SRC \\
\hline Walk-In Storage Wall Insulation U-value & 0.65 \\
Roof Insulation U-Value & 0.31 \\
Warehouse Clerestory WWR & -0.30 \\
Warehouse Heating Temperature Setpoint & 0.27 \\
Chilled Storage Defrost Control & -0.22 \\
Office Plug Load Density & 0.22 \\
Warehouse Lighting Average Power Density & 0.19 \\
Warehouse Cooling Temperature Setpoint & -0.16 \\
Frozen Storage - Refrigeration System Rated COP & -0.15 \\
External Wall Insulation U-value & 0.15 \\
Roof Thermal Mass Heat Capacity & -0.14 \\
Frozen Storage Defrost Control & -0.14 \\
Building Occupancy Sensor Control & -0.11 \\
Building Infiltration Rate & 0.11 \\
External Wall Thermal Mass Heat Capacity & -0.11 \\
\hline
\end{tabular}

TableB.3. 15 most sensitive terms in the bilinear sensitivity analysis for Asuncion

\begin{tabular}{ll}
\hline Main Effect/Interaction & SRC \\
\hline Walk-In Storage Wall Insulation U-value & 0.62 \\
Roof Solar Absorptance & 0.35 \\
Warehouse Cooling Temperature Setpoint & -0.29 \\
Warehouse Clerestory WWR & -0.27 \\
Roof Insulation U-Value & 0.23 \\
Office Plug Load Density & 0.21 \\
\hline
\end{tabular}




\begin{tabular}{ll}
\hline Chilled Storage Defrost Control & -0.18 \\
Warehouse Lighting Average Power Density & 0.18 \\
Roof Thermal Mass Heat Capacity & -0.17 \\
Roof Insulation U-Value * Roof Solar Absorptance & 0.16 \\
External Wall Solar Absorptance & 0.15 \\
Frozen Storage - Refrigeration System Rated COP & -0.15 \\
Roof Solar Absorptance * Warehouse Cooling Temperature Setpoint & -0.14 \\
External Wall Insulation U-value & 0.13 \\
Building Occupancy Sensor Control & -0.11 \\
\hline
\end{tabular}

TableB.4. 15 most sensitive terms in the bilinear sensitivity analysis for Mombasa

\begin{tabular}{ll}
\hline Main Effect/Interaction & SRC \\
\hline Walk-In Storage Wall Insulation U-value & 0.52 \\
Roof Solar Absorptance & 0.44 \\
Warehouse Cooling Temperature Setpoint & -0.38 \\
External Wall Solar Absorptance & 0.21 \\
Roof Solar Absorptance * Warehouse Cooling Temperature Setpoint & -0.18 \\
Roof Insulation U-Value & 0.17 \\
Office Plug Load Density & 0.17 \\
Roof Insulation U-Value * Roof Solar Absorptance & 0.16 \\
Warehouse Lighting Average Power Density & 0.15 \\
Warehouse Clerestory WWR & -0.14 \\
Chilled Storage Defrost Control & -0.12 \\
External Wall Insulation U-value & 0.11 \\
Frozen Storage - Refrigeration System Rated COP & -0.11 \\
Roof Thermal Mass Heat Capacity & -0.10 \\
Building Occupancy Sensor Control & -0.10 \\
\hline
\end{tabular}

Table B.5. 15 most sensitive terms in the bilinear sensitivity analysis for Bangkok

\begin{tabular}{ll}
\hline Main Effect/Interaction & SRC \\
\hline Warehouse Cooling Temperature Setpoint & -0.50 \\
Roof Solar Absorptance & 0.49 \\
Walk-In Storage Wall Insulation U-value & 0.37 \\
External Wall Solar Absorptance & 0.25 \\
Roof Insulation U-Value & 0.23 \\
Roof Insulation U-Value * Roof Solar Absorptance & 0.19 \\
Roof Solar Absorptance * Warehouse Cooling Temperature Setpoint & -0.15 \\
External Wall Insulation U-value & 0.14 \\
Warehouse Lighting Average Power Density & 0.12 \\
Building Infiltration Rate & 0.11 \\
Office Plug Load Density & 0.11 \\
A/C System - Average COP & -0.10 \\
Warehouse Clerestory WWR & -0.10 \\
External Wall Insulation U-value * External Wall Solar Absorptance & 0.10 \\
Roof Thermal Mass Heat Capacity & -0.09 \\
\hline
\end{tabular}




\section{References}

1. IEA. IEA SHC Task 40/ECBCS Annex 52: Towards net zero energy solar buildings. 2008. Accessed: Mar. 5, 2014; Available from: http://task40.iea-shc.org/.

2. UK-GBC. UK-GBC Task Group Report: Building Zero Carbon - the case for action. 2014. Accessed: June 5, 2014; Available from:http://www.ukgbc.org/resources/publications.

3. DOE, U. Building Technologies Program, Planned Program Activities for 2008-2012. 2008. Accessed: Feb. 16, 2014; Available from: http://apps1.eere.energy.gov/buildings/publications/.

4. Marseille, T., Essential Methods, Models and Metrics for Net Zero Energy Buildings. ASHRAE Transactions, 2011. 117(1): p. 389-397.

5. Torcellini, P.A., et al., Zero energy buildings: A critical look at the definition. 2006, NREL: Golden, CO.

6. Hansen, H. and M.-A. Knudstrup, Parametric analysis as a methodical approach that facilitates the exploration of the creative space in low-energy and zero-energy design projects, in 25th Conference on Passive and Low Energy Architecture. 2008: Dublin, Ireland, October 22-24.

7. Belleri, A., R. Lollini, and S.M. Dutton, Natural ventilation design: An analysis of predicted and measured performance. Building and Environment, 2014. 81: p. 123-138.

8. Seo, S., C.-H. Wang, and G. Grozev, Cooling energy consumption and reduction effect for residential buildings in South East Queensland, Australia. Building and Environment, 2013. 59: p. 408-416.

9. Shen, H. and A. Tzempelikos, Sensitivity analysis on daylighting and energy performance of perimeter offices with automated shading. Building and Environment, 2013. 59: p. 303-314.

10. Hygh, J.S., et al., Multivariate regression as an energy assessment tool in early building design. Building and Environment, 2012. 57: p. 165-175.

11. 12. Attia, S., et al., Achieving informed decision-making for net zero energy buildings design using building performance simulation tools. Building Simulation, 2013. 6(1): p. 3-21.

13. Heller, J., M. Heater, and M. Frankel, Sensitivity Analysis: comparing the impact of design, operation, and tenant behavior on building energy performance. 2011, NBI.

14. Wang, L., P. Mathew, and X. Pang, Uncertainties in energy consumption introduced by building operations and weather for a medium-size office building. Energy and Buildings, 2012. 53: p. 152-158.

15. Ruiz, R., S. Bertangolio, and V. Lemort, Global sensitivity analysis applied to total energy use in buildings, in International High Performance Buildings Conference at Purdue. 2012: Purdue.

16. Hackel, S. and S. Schuetter, Best practices for commissioning automatic daylighting controls. ASHRAE Journal, 2013. 55(9): p. 46-56.

17. NREL, The design-build process for the research support facility. 2012.

18. Domínguez-Muñoz, F., J.M. Cejudo-López, and A. Carrillo-Andrés, Uncertainty in peak cooling load calculations. Energy and Buildings, 2010. 42(7): p. 1010-1018.

19. Jaffal, I., C. Inard, and C. Ghiaus, Fast method to predict building heating demand based on the design of experiments. Energy and Buildings, 2009. 41(6): p. 669-677. 
20. Garnett, A., Guideline for establishing or improving primary and internediate vaccine stores. 2002, WHO: Geneva, Switzerland.

21. Dillon, K., and J. Colton, A Design Methodology for the Economic Design of Vaccine Warehouses in the Developing World, Building and Environment, 2014. 82: p. 160-170.

22. Pudleiner, D., Using Uncertainty and Senstivty Analysis to Inform the Deisgn of Net-Zero Energy Vaccine Warehouses, in Mechanical Engineering. 2014, Georgia Tech.

23. LBNL. EnergyPlus Validation Reports. 2014. Accessed: Jan 9, 2014; Available from: http://simulationresearch.lbl.gov/dirpubs/valid_ep.html.

24. de Wilde, P., W. Tian, and G. Augenbroe, Longitudinal prediction of the operational energy use of buildings. Building and Environment, 2011. 46(8): p. 1670-1680.

25. Tian, W., A review of sensitivity analysis methods in building energy analysis. Renewable \& Sustainable Energy Reviews, 2013. 20: p. 411-419.

26. PATH Meeting Requirements for Controlled Room Temperature Storage of Medicines. 2012.

27. ISO, Internation Standard 13790: Energy performance of buildings - Calculation of energy use for space heating and cooling. 2008.

28. Jungheinrich. EJC 212 Lift Truck. 2013. Accessed: June 17, 2013; Available from: www.jungheinrich.co.uk.

29. Argonne National Labs, Full Fuel-Cycle Comparison of Forklift Propulsion Systems. 2008.

30. LBNL, EnergyPlus Engineering Reference. 2013.

31. Stoeckle, R., Refrigerated warehouse operation under real-time pricing, in Mechanical Engineering. 2000, University of Wisconsin - Madison.

32. Liu, B., et al., Technical Support Document - The Development of the Advanced Energy Design Guide for Small Warehouse and Self-Storage Buildings. 2007, Pacific Northwest National Laboratory.

33. ASHRAE Advanced energy design guide for small warehouses and self storage buildings. 2008.

34. Helton, J.C., et al., Survey of sampling-based methods for uncertainty and sensitivity analysis. Reliability Engineering \& System Safety, 2006. 91(10-11): p. 1175-1209.

35. Macdonald, I.A., Quantifying the effects of uncertainty in building simulation, in Mechanical Engineering. 2002, University of Strathclyde.

36. Jaccard, J., Interaction effects in multiple regression. Quantitative applications in the social sciences ;, ed. R. Turrisi and C.K. Wan. 1990, Sage Publications: Newbury Park.

37. Morris, M., Factorial Sampling Plans for Preliminary Computational Experiments. Technometrics, 1991. 33(2): p. 161-174.

38. USAID. List of Advanced Developing Countries. 2012. Accessed: Jan 14, 2014; Available from: http://www.usaid.gov/sites/default/files/documents/1876/310mab.pdf.

39. USAID. List of Developing Countries. 2012 Accessed: Jan 14, 2014; Available from: http://www.usaid.gov/sites/default/files/documents/1876/310maa.pdf

40. ASHRAE, ASHRAE Standard 90.1-2007 Normative Appendix B - Building Envelope Climate Criteria. 2007.

41. Deru, M. and P. Torcellini, Improving Sustainability of Buildings Through a Performance-Based Design Approach: Preprint. , in World Renewable Energy Congress VIII, 29 August--3 September 2004. 2004: Denver, Colorado p. 8. 
42. Saltelli, A., K. Chan, and E. Scott, Sensitivity Analysis in Practice. 2004, UK: John Wiley \& Sons.

43. Givoni, B., Comfort, climate analysis and building design guidelines. Energy \& Buildings, 1992. 18: p. 11-23.

44. Leach, M., et al., Grocery store 50\% energy savings, technical support document. 2009, NREL. 